\title{
revista internacjonal

\section{El reconocimiento del Código de la Familia Marroquí en Francia y su impacto sobre las mujeres migrantes marroquíes ${ }^{1}$}

\author{
Recognition of the Moroccan Family Code in France and \\ the impact on Moroccan migrant women
}

\author{
Félix Fernández Castaño ${ }^{1}$ \\ María Teresa González Santos². \\ ${ }^{1}$ Profesor Departamento de Sociología, Universidad de Granada, Granada, \\ España. \\ ${ }^{2}$ Doctoranda Departamento de Sociología, Universidad de Granada, \\ Granada, España.
}

Correspondencia: Félix Fernández Castaño. Facultad de Ciencias Políticas y Sociología, C/ Rector López Argüeta s/n.18071 Granada. España. E-mail: felixfernandez@ugr.es

(C) Revista Internacional de Estudios Migratorios. CEMyRI. UAL (España)

\footnotetext{
${ }^{1}$ Este artículo forma parte de nuestra Tesis doctoral, en curso, titulada "Las trayectorias migratorias de las mujeres marroquíes migrantes en la UE-Francia". Inscrita en el Programa de Doctorado en Ciencias Sociales. Departamento de Sociología. Universidad de Granada.
} 


\section{Resumen}

El presente trabajo pretende estudiar las tradiciones jurídicas francesa y marroquí, y su coexistencia en territorio francés, facilitada por la firma del Convenio Bilateral entre Marruecos y Francia. La aplicación de un doble sistema jurídico -francés y marroquí-, a la comunidad marroquí inmigrante en Francia, tiene unas repercusiones, que en el caso de las mujeres, las conduce a diversas situaciones que las relegan a posiciones de subordinación, dependencia y doble violencia. En función de todo ello, dos son los objetivos de este trabajo: el primero, se dirige a estudiar las tradiciones jurídicas en las que se basan los sistemas de derecho francés y marroquí, así como su funcionamiento conjunto; el segundo, es analizar el impacto que el reconocimiento del Código de la Familia Marroquí ejerce sobre mujeres marroquíes migrantes en Francia. La metodología está basada en una revisión bibliográfica que comprende una serie de textos especializados sobre el funcionamiento de los sistemas jurídicos desde de la perspectiva de la sociología del derecho (Carbonnier, 1994; Fariñas, 1991 y 1996; Soriano, 1997; Weber, 2005;). En referencia al impacto del reconocimiento del derecho marroquí en el país de destino, los análisis están fundamentados en bibliografías que se ocupan de los aspectos de género y migración.

Palabras clave: Código de Familia Marroquí, reconocimiento, Francia, impacto, mujeres marroquíes migrantes. 


\begin{abstract}
This paper aims to study the French and Moroccan legal traditions, and their coexistence in French territory, facilitated by the signing of the bilateral agreement between Morocco and France. The application of a dual legal system -French and Moroccan-, to a Moroccan immigrant community in France, has an impact, which in the case of women, they lead them to various situations that relegate them to subordinate positions, dependency and double violence. Based on all this, there are two objectives of this work: the first is aimed at studying the legal traditions in which both systems, French and Moroccan law is based, and how they work together; the second, to analyse the impact that recognition of the Moroccan Family Code has on Moroccan women migrants in France. The methodology is based on a literature review that includes a series of texts specialized on the functioning of legal systems from the perspective of the sociology of law (Carbonnier, 1994; Fariñas, 1991 and 1996; Soriano, 1997; Weber, 2005) Referring to the impact of the recognition of Moroccan law in the country of destination, the analyses are based on bibliographies dealing with gender issues and migration.
\end{abstract}

Keywords: Moroccan Family Code, recognition, France, impact, Moroccan migrant women. 


\section{Introducción}

La moderna migración desde el Magreb y el África subsahariana hacia la Unión Europea y en concreto en Francia, goza de una especificidad que emana de la práctica de su cultura y de su religión- la musulmana-, que representa hoy la segunda religión de Francia. Alrededor de 6 millones de musulmanes residían en Francia en 2011, y en 2010 más de 44 millones lo hacían en la $\mathrm{UE}^{2}$. Este escenario exige unas políticas concretas por parte de los Estados de las sociedades de destino de las poblaciones musulmanas, tales como el reconocimiento de los sistemas jurídicos vigentes en los países de origen de tipo confesional, en contraposición con los sistemas jurídicos de derecho positivo o constitucional de las sociedades de destino, es decir, la Unión Europea y Francia. Por una parte, el Estado de derecho reconoce la aplicación de todas las leyes y normas que garantizan el orden público a toda la población, incluida la población inmigrada; y por otra, la integración plena supone el respeto a la diversidad cultural por parte de los Estados occidentales modernos, que pretenden la regulación de las comunidades inmigradas en cuanto a las prácticas religiosas que las acompañan. La cuestión de la laicidad del Estado en Francia viene marcada por la ley del 9 de diciembre de 1905 y por la Constitución de 1958 que regulan la separación entre Iglesia y Estado (Hochart, 1998). Por lo tanto, las instituciones del Estado mantienen una posición de neutralidad en relación a todas las confesiones religiosas, relegando su práctica a la esfera privada de los individuos. Así, el papel desempeñado por el Estado es únicamente el de salvaguardar la libertad religiosa y de conciencia. La integración de los y las inmigrantes musulmanes, requiere una perspectiva singular en materia de reconocimiento del derecho personal y de familia, ya que éste refleja la tradición islámica de la que emana. La coexistencia entre dos culturas, la una aconfesional y la otra religiosa, pone en juego dos sistemas jurídicos que se oponen, creando una yuxtaposición de culturas jurídicas que genera no pocas situaciones conflictuales: por un lado, el mundo occidental organizado en sistemas jurídico-políticos secularizados, pluralistas, liberales, donde el derecho privado es laico y moderno; y por otro, la civilización islámica basada en las verdades reveladas y la sumisión a Dios. El derecho musulmán tiene su origen en la tradición revelada al Profeta Mahoma y goza de una originalidad que viene dada por la unicidad de las reglas jurídicas y religiosas, encontrándose éstas, íntimamente ligadas. Este derecho no es homogéneo, pues se

\footnotetext{
${ }^{2}$ Fuentes: Eurostat y elmundo.es, consultadas en línea el 09/06/2015.
} 
encuentra en varias escuelas coránicas -hanbalí, malikí, shafií y hanafí-. Durante la época colonial, el derecho musulmán ( $f i q h$ ) tuvo que abrirse a la racionalidad jurídica occidental, sobre todo en derecho económico y público, pues éstos eran inexistentes o inadecuados (Coulson, 1998). Sin embargo, en materia de relaciones familiares, la ley islámica (Sharía) se mantuvo y su pervivencia ha llegado hasta la actualidad, en un proceso que ocupó, en el caso marroquí, sucesivas reformas -la última en 2004-, pasando a denominarse Código de la Familia. El Código recoge la concepción jurídica de las relaciones de familia y contiene especificaciones en materia de matrimonio, divorcio, nacimientos, capacidad jurídica y tutoría legal, testamento y herencia. Su fuente de derecho es la Shari'a y se basa en los preceptos de la escuela malikí emanada de las corrientes tradicionistas más rígidas. Ésta, se caracteriza por situar a la mujer en una posición de subordinación frente al hombre, aunque después de la reforma, se establece una relación de igualdad entre los sexos frente al matrimonio y en el matrimonio. Aunque la reforma mejora la situación de las mujeres, mantiene figuras como el repudio y la poligamia como prácticas que refuerzan la posición dominante de los varones, constituyendo elementos de plena desigualdad entre hombres y mujeres.

En virtud de la importante comunidad marroquí inmigrada en Francia en la actualidad, nos planteamos los siguientes interrogantes: ¿pueden coexistir dos tradiciones jurídicas contrapuestas, la una laica y la otra religiosa?; y ¿cuál es el impacto del reconocimiento del Código de Familia Marroquí sobre las mujeres marroquíes migrantes en Francia?

En función de todo ello, y para despejar las incógnitas de nuestro estudio, dos son los objetivos de este trabajo: el primero, se dirige a estudiar las tradiciones jurídicas en las que se basan los sistemas de derecho francés y marroquí, así como su funcionamiento conjunto; el segundo, es analizar el impacto que el reconocimiento del Código de la Familia Marroquí ejerce sobre mujeres marroquíes migrantes en Francia. La metodología que utilizaremos está basada en una exhaustiva revisión bibliográfica que comprende una serie de textos especializados sobre el funcionamiento de los sistemas jurídicos desde de la perspectiva de la sociología del derecho (Carbonnier, 1994; Fariñas, 1991 y 1996; Soriano, 1997; Weber, 2005;). En referencia al impacto del reconocimiento del 
derecho marroquí en el país de destino, los análisis están fundamentados en bibliografías francesa y marroquí, haciendo énfasis en los aspectos de género y migración. Pasamos inmediatamente a la presentación de los distintos apartados que articulan el presente trabajo. Tras esta introducción, en el apartado segundo, presentamos un panorama teórico orientado a explicar las tradiciones jurídicas de Francia y Marruecos, a través de los autores que se han ocupado de la sociología del derecho, una disciplina reciente que ha dado un nuevo giro a las ciencias jurídicas. El tercer apartado, consta de una descripción histórica y conceptual del Código de Familia Marroquí, pasando por las diversas reformas efectuadas por el Estado marroquí hasta la actualidad y de su aspecto conceptual, con respecto a sus contenidos y regulaciones. En el cuarto apartado, exponemos las necesidades de las poblaciones marroquíes inmigradas en Francia y las políticas de ésta para hacer frente a las demandas jurídicas de los y las marroquíes, a través de los Convenios Bilaterales. Por último, analizamos el impacto y los efectos que el reconocimiento de la ley marroquí ejerce sobre las mujeres marroquíes migrantes en Francia. Finalmente, realizamos unas conclusiones que cierran nuestro estudio sobre la problemática del reconocimiento de los códigos extranjeros en los países de destino de la UE, y el impacto sobre las mujeres inmigrantes, concretamente, en Francia.

\section{Derecho, sociedad e inmigración}

El derecho histórico y las tradiciones jurídicas fueron analizadas por Max Weber, que construyó la teoría de los tipos ideales del derecho, estableciendo cuatro categorías: racional, irracional, formal y material. La categoría racional significa que el derecho se apoya en principios generales y está organizado sistemáticamente. La categoría de irracional se refiere a que sus principios se basan en una lógica, pero este derecho no está sistematizado. La categoría formal se designa cuando sus fundamentos son criterios netamente jurídicos. Y, por último, la categoría material del derecho indica que sus principios son extrajurídicos, es decir, son de orden religioso, moral o político. Estas cuatro categorías se pueden cruzar y, en nuestro caso, los tipos ideales del derecho que rigen los sistemas jurídicos francés y marroquí, se podrían encuadrar, según la tipología de Weber, en el sistema racional-formal que define el derecho positivo 
francés, y en un sistema irracional-material como es el sistema jurídico marroquí, representado por la "justicia del Cadí” (Weber, 2005).

De esta forma tenemos, de una parte, el sistema jurídico francés de tipo racionalformal, que es el que posee mayor grado de racionalización debido a la conformación de un sistema, a partir del cual, las decisiones emanan de la deducción de los principios básicos establecidos de forma explícita. Además, posee una formalización, ya que el derecho está separado de la ideología, de la religión y de la moral. Así, mencionamos los dos aspectos fundamentales del derecho racional-formal: uno, la aplicación de un precepto abstracto a una cuestión concreta, produciendo así una decisión jurídica; y otro, que este derecho es el que posee el nivel más elevado de racionalidad metódica. El derecho racional-formal es propio de la civilización occidental por su rasgo racionalizador, característico de occidente. De otra parte, el sistema jurídico marroquí de tipo irracional-material, es propio de sociedades tradicionales, tales como las grandes civilizaciones antiguas. En este tipo de sistema, el Cadí, representaba la figura del juez en el Imperio Otomano y aplicaba la justicia dependiendo de principios morales o de aspectos políticos. No es racional, ya que no tiene una organización específica de sus principios, aunque sus fuentes sean los textos sagrados. Es material, porque sus principios no son exclusivamente jurídicos y están basados en el sentido común, los programas políticos o la moral (Fariñas, 1991). 
Asimismo, para explicar las implicaciones que los sistemas jurídicos ejercen sobre la sociedad y los individuos, utilizaremos la perspectiva de la sociología del derecho, ya que ésta, tiene como objeto el estudio la posición del derecho en la sociedad y la función que éste ejerce en el seno de la aquélla, de sus reglas e instituciones, y los efectos que todo ello produce en las conductas sociales y en las respuestas sociales generadas hacia las regulaciones formales del derecho. Es decir, la sociología del derecho intenta explicar la influencia de los factores sociales en el derecho y la repercusión del derecho en la sociedad (Soriano, 1997). Por este motivo, la sociología jurídica necesita conceptualizar los sistemas sociales y jurídicos, siendo el primero un sistema que se desarrolla en un espacio donde tienen lugar las interacciones entre los individuos, mientras que, el segundo, desde la perspectiva socio-jurídica, es un sistema que posee símbolos normativos que tienen como función persuadir, actuando como generadores de los comportamientos sociales (Fariñas, 1996).

Pero, no podemos obviar que un sistema jurídico que ocupa un territorio coincidente con el Estado y lo identifica, no es del todo monista e intocable, ya que pueden producirse fenómenos de ocupación y vigencia de otros sistemas jurídicos, tales como los estatutos de una asociación que rigen la vida y el funcionamiento de ésta o la validez y reconocimiento de otros sistemas extranjeros, operados por el Derecho Internacional Privado. De este modo, puede haber leyes extranjeras que hagan competencia a una ley estatal y que el Estado delegue en ellas y le abra un espacio jurídico válido. Este fenómeno de pluralismo jurídico nos muestra cómo en un mismo Estado pueden coexistir uno o varios sistemas jurídicos extraños a la soberanía de un territorio (Carbonnier, 1994). Desde esta perspectiva, el reconocimiento del Código de la Familia Marroquí en Francia, es efectuado por el Estado francés mediante el denominado Convenio Bilateral de 10 de agosto de 1981, firmado por el Reino de Marruecos y la República francesa. Este Convenio tiene la función de reconocer en el país de destino, a los matrimonios musulmanes celebrados en Marruecos, así como de todas las regulaciones que atañen a la unidad familiar marroquí, con el fin de conservar su especificidad, en materia de derechos derivados del ejercicio de la cultura musulmana. El gran número de nacionales marroquíes inmigrados en Francia, desde hace varias décadas, requirió la coexistencia de dos sistemas jurídicos aún opuestos entre sí, por los valores que fundamentan los cimientos de ambos sistemas, siendo contrarios y contradictorios. Esto provoca múltiples situaciones que ponen contra las 
cuerdas a los jueces y juristas franceses, a la hora de la aplicación de las leyes marroquíes, contrarias al espíritu del derecho francés, y también, a los sujetos a los que se le aplica el Código de la Familia, siendo casi siempre las mujeres las más afectadas y las perdedoras, debido a las resoluciones producidas por la ley marroquí, que las sitúa en posiciones de partida subordinadas, causadas por los valores de complementariedad de los sexos y de la especificidad de éstos, contemplados en el Código marroquí.

\section{Antecedentes históricos y conceptuales del Código de la Familia Marroquí}

Los Códigos de Estatuto Personal o Código de la Familia, regulan las relaciones familiares en todas las sociedades árabes y este conjunto de normas se fundamenta en la ley sagrada o Sharía. El derecho islámico posee un carácter religioso, debido a su origen divino. Sin embargo, la mayoría de los países musulmanes tienen sus propios códigos de derecho positivo, es decir, penal, civil, mercantil y constitucional. El derecho constitucional de estos países establece la igualdad entre los sexos, frente a los Códigos de Estatuto Personal que perpetúan el modelo patriarcal de organización familiar de obediencia de la esposa al esposo. En el caso de Marruecos, la reforma del Código llevada a cabo en 2004, establece la igualdad de los esposos que, como veremos, no es aplicada completamente, dando lugar a situaciones que contravienen los Convenios Internacionales de Derechos y de defensa contra las discriminaciones hacia las mujeres, firmados y ratificados por el Estado Marroquí (Ajaaouani, 2012; Ruiz de Almodóvar, 2005;).

La institución del Código de Estatuto Personal en Marruecos - denominado hoy Código de la Familia, en adelante CF-, remonta a la independencia del país en 1957, entrando en vigor en 1958. El Código se fundamenta en la doctrina ortodoxa, es decir, la sunní que carece de instituciones eclesiásticas y que se dispone en cuatro Escuelas de Derecho Islámico. Éstas ofrecen respuestas para la sociedad islámica en los aspectos religioso, económico, social o político, que pasamos a enumerar rápidamente: la escuela hanafí fundada en Irak por Abu Hanifa (m. 150/767) da importancia a la opinión personal o ra'y y a la analogía metodológica o qiyas, ésta última aplica una disposición ya existente en las fuentes a un caso no previsto en ellas; la escuela malikí fundada en Medina por Malik b. Anas (m. 179/795) se apoya en el Corán y la sunna (dichos y hechos del Profeta) como fuentes, casi exclusivamente; la escuela shafí $i$, de Muhammad b. Idris al-Safi (m.204/820) basada en las tradiciones del Corán y la sunna, 
utiliza, además, tanto el fiqh (ciencia del derecho islámico) como la iyma o consenso general de la comunidad; y por último, la escuela hanbalí ideada por Ahmad b. Hanbal (m. 241/855) la más tradicionista, rechaza toda innovación y limita al máximo el ráy y la qiyas, hace casi un uso exclusivo del Corán y la sunna como fuentes de derecho (Milliot y Blanc, 2001; Pareja, 1954). Las escuelas más tradicionistas son la hanbalí y la malikí, siendo la escuela hanafí la más liberal y la shafi 'í una vía intermedia.

Así, el CF se inspira en la Escuela Jurídica malikí, basada en las dos obras fundamentales del Derecho Islámico: la Al-Mawatta (pilar básico de la jurisprudencia islámica) y la Al-Mudawana. El pensamiento de la Escuela malikí se inscribe en el CF de forma que lo que no esté plasmado en el Código, se resolverá por los valores de igualdad, convivencia pacífica y justicia (Ortiz, 2014). Esta Escuela fue instaurada en Al-Ándalus a través de la invasión árabe de la Península Ibérica desde 711 a 1609, con la expulsión definitiva de los moriscos (Martínez Almira, 2006), siendo hoy la que impera en todos los países del norte de África, Kuwait y África negra y ha favorecido el resurgimiento de supersticiones y de las costumbres populares (Maíllo Salgado, 2005). Tras las dos reformas practicadas desde su instauración -la primera en 1993 y la segunda en 2004-, a instancias de los movimientos sociales, entre los cuales se encontraban las asociaciones feministas y de Derechos Humanos, se movilizaron para pedir justicia y la igualdad de los sexos, logrando con ello una situación de modernización religiosa, social y política.

En virtud de la importante comunidad marroquí inmigrada en Francia en la actualidad, nos planteamos los siguientes interrogantes: ¿pueden coexistir dos tradiciones jurídicas contrapuestas, la una laica y la otra religiosa?; y ¿cuál es el impacto del reconocimiento del Código de Familia Marroquí sobre las mujeres marroquíes migrantes en Francia?

Concretamente, y para despejar las incógnitas de nuestra investigación, enumeramos los objetivos de nuestro estudio: el primero, se dirige a estudiar las tradiciones jurídicas en las que se basan los sistemas de derecho francés y marroquí, así como su funcionamiento conjunto; el segundo, es analizar el impacto que el reconocimiento del Código de la Familia Marroquí ejerce sobre mujeres marroquíes migrantes en Francia. La metodología que utilizaremos está basada en una exhaustiva 
revisión bibliográfica que comprende una serie de textos especializados sobre el funcionamiento de los sistemas jurídicos desde de la perspectiva de la sociología del derecho (Carbonnier, 1994; Fariñas, 1991 y 1996; Soriano, 1997; Weber, 2005;). En referencia al impacto del reconocimiento del derecho marroquí en el país de destino, los análisis están fundamentados en bibliografías francesa y marroquí, haciendo énfasis en los aspectos de género y migración. En concreto, la última reforma se fundamenta en la abolición de la desigualdad entre mujeres y hombres, proponiendo así, nuevos derechos, y estos son: la igualdad en la edad de matrimonio a los 18 años; la supresión de la tutela matrimonial; el reconocimiento de la representación legal de las mujeres; la disolución del matrimonio bajo el control del juez; el derecho de guarda de los hijos en función de los intereses del menor; y el reconocimiento del matrimonio civil para los Residentes Marroquíes en el Extranjero (Benradi, 2004). Esto significó la voluntad de una interpretación de la ley islámica abierta, fundamentándose en la Shari a como fuente de derecho principal y, al mismo tiempo, poniéndola en relación con el interés público. Al mismo tiempo, se ha conectado con la asunción de los Convenios Internacionales firmados por Marruecos, que contienen los valores universales de equidad, cooperación, tolerancia y justicia (Esteban de la Rosa, 2009). 
Así, tanto el contenido como la estructura del CF, están dispuestos en 7 partes y cada una de ellas se denomina Libro. Cada Libro recoge los siguientes aspectos:

1.- Matrimonio: está organizado en 6 capítulos y tratan del matrimonio, la capacidad y los requisitos para la celebración del matrimonio, comprende los artículos 9- 69.

2.- Divorcio: Se estructura en 8 capítulos que tratan de la disolución matrimonial y sus consecuencias, ocupa los artículos 70-141.

3.- Nacimientos: está formado por 3 capítulos y se ocupan del nacimiento y de los efectos en que éste pueda derivar. Son los artículos 142-205.

4.- Capacidad jurídica y tutoría legal: en 3 capítulos, trata de la capacitación, de la incapacitación y del incapacitado. Abarca los artículos 206-276.

5.- Testamento: se ocupa de éste en 6 capítulos. Artículos 321-395.

6.- Herencia: normativiza la sucesión en 10 capítulos en los artículos 321-395.

7.- Disposiciones transitorias y finales: deroga el anterior Código de Estatuto Personal de 1957. Y todas las disposiciones que contravengan al CF. (Esteban de la Rosa, 2009; Ruiz de Almodóvar, 2005;).

Aunque el nuevo CF haya enmendado numerosos artículos que mantenían una sociedad tradicional y desigualitaria, en lo que se refiere a la posición de las mujeres, todavía existen preceptos que vulneran la equiparación entre los géneros, tales como la disolución del matrimonio y la poligamia.

\section{Las necesidades de la migración marroquí y la traslación del CF hacia la UE- Francia: los Convenios Bilaterales}

El fenómeno migratorio hacia Europa tuvo consecuencias como el asentamiento de comunidades con tradiciones y culturas bien distintas a la tradición europea. Fruto de los procesos de descolonización y de las necesidades de mano de obra para su reconstrucción al término de la II Guerra Mundial, se produjeron grandes movimientos migratorios que fueron asentándose de forma definitiva, con lo que Europa, tuvo que dar respuestas concretas a las necesidades de estas comunidades. Así, el mundo islámico y la cultura occidental tuvieron dificultades a la hora de ofrecer una solución a los problemas derivados de las relaciones de familia en lo que atañe a divorcios, herencias o matrimonios mixtos. En este último caso, los distintos estatutos jurídicos de base personal que regulaban las relaciones entre los esposos, podrían suscitar controversias al 
producirse diferencias en la permisividad entre los distintos sistemas jurídicos que afectaban a unos y otros.

Concretamente, la inmigración marroquí toma todo su protagonismo, a partir de la primera gran ola migratoria a principios de la década de los 60. Su naturaleza se origina en el proceso de descolonización efectuado por Francia y que culminó con la independencia de Marruecos en 1957. La comunidad migrante marroquí se va instalando en suelo francés a lo largo de un proceso que se estructura en las distintas olas migratorias, desde el país de origen, Marruecos, hacia el país de destino, Francia. Desde esta perspectiva, la estabilización de la comunidad marroquí pasa por el reconocimiento de las regulaciones contenidas en el sistema jurídico marroquí, a partir del Código de Estatuto Personal, que rige las relaciones de familia. Conscientes de este hecho, las autoridades francesas ponen en marcha un Convenio Bilateral entre Marruecos y Francia, basado en el Convenio franco-marroquí de 10 de agosto de 1981 y la Convención entre la República Francesa y el Reino de Marruecos relativa al estatuto de las personas y de la familia y la cooperación judicial, con entrada en vigor en junio de 1983. Este Convenio, en su artículo 1º expone “El Estado y la capacidad de las personas físicas están regidos por la ley del Estado donde estas personas tengan la nacionalidad", por lo que se reconoce expresamente la aplicación del derecho de los extranjeros vinculado a su nacionalidad. Pero, existen dificultades en la aplicación del derecho de familia marroquí por los tribunales y jueces franceses, propugnada por las leyes de Derecho Internacional Privado, esto es, entre el ordenamiento jurídico francés y la asunción del CF, por presentar contradicciones.

Desde la técnica jurídica, en Derecho Internacional Privado, Francia tiene la obligación de favorecer la armonía en la defensa del orden público internacional y al mismo tiempo, tiene la obligación de defender el derecho interno para preservar su cohesión, en virtud de los valores de igualdad y de respeto a los Derechos Humanos. Desde el plano ideológico, el sistema jurídico francés basa su tradición en el respeto a los valores emanados de los Derechos Humanos y la universalidad, mientras que, los sistemas jurídicos con tradiciones culturales distintas defienden el relativismo cultural y el derecho a la identidad cultural. En lo que se refiere a la cuestión de la igualdad entre los sexos, el sistema jurídico marroquí se fundamenta en la complementariedad de los sexos y en la especifidad de la ley islámica, como fuente de derecho del CF. Esta misma 
cuestión se plantea en el sistema jurídico francés de forma que, la igualdad entre los sexos, tiene su raíz en derechos y deberes (Najm, 2009).

Desde la perspectiva de la aplicación del Convenio Bilateral Franco-marroquí, el liberalismo ejercido por Francia, como país de inmigración en el reconocimiento del Código de Estatuto Personal, denominado hoy Código de la Familia marroquí (CF), recoge prácticas como la disolución del matrimonio islámico y la poligamia. La gran diversidad ideológica tendrá que ser el punto de inflexión para dar soluciones a las controversias suscitadas en materia de divorcio en las comunidades inmigradas en Francia, pues las dificultades que se originan sobre el derecho interno, proceden de algunos elementos extraños presentes en la legislación marroquí, como son la disolución del matrimonio islámico y la práctica de la poligamia.

\subsection{La disolución del matrimonio islámico por talaq y tatliq}

En la Introducción al CF realizada por Esteban de la Rosa, Ouhida, Ouald Ali y Saghir (2009), en el párrafo 12 respecto a la disolución del contrato matrimonial, éste dice que es disuelto de forma unilateral por parte del esposo: "[...] el CF permite al esposo la disolución unilateral del matrimonio, ha limitado este derecho estableciendo un procedimiento complicado para impedir que pueda abusar de dicha facultad o prerrogativa, quedando la mujer en un segundo plano". En el derecho islámico clásico la práctica unilateral es exclusiva, está en vigor en la mayoría de los países musulmanes y proviene de la época pre-islámica, perteneciendo al esposo el derecho de ruptura del matrimonio. En la época anterior al Profeta, la disolución matrimonial por talaq, estaba muy extendida entre los árabes y significaba para el hombre el abandono inmediato y definitivo de la esposa y de todos los derechos asociados al matrimonio (Juynboll, 2002). En esta época, la disolución de la vida conyugal mediada por un juez, era considerada como una práctica que atentaba contra el derecho del marido, ya que las mujeres eran consideradas como objeto del propio contrato matrimonial (Milliot y Blanc, 2001). Esta disolución matrimonial contradice el principio de igualdad entre los esposos y desestabiliza la convivencia conyugal. El escenario clásico en los juzgados franceses cuando es de aplicación el CF es que la mujer que ha sido abandonada por su marido, se dirige al juez francés para demandar el divorcio o para condenar al marido a la contribución de las cargas pecuniarias del matrimonio. Contra esta acción era muy probable que el marido consiguiera un acta legal de disolución matrimonial en su país 
de origen mediante un viaje. Desde esta situación, los tribunales franceses se veían en una situación conflictual entre la aplicación de las leyes extranjeras, ya que éstas contravienen los principios fundamentales y los valores del derecho francés, con respecto al tratamiento de igualdad entre los esposos (Najm, 2009). A partir de la reforma de 2004, la mujer también puede disolver el vínculo conyugal, pues el Artículo 78 del CF dice: la disolución del matrimonio por talaq consiste en la extinción del pacto del matrimonio a instancia del esposo o de la esposa, de conformidad con los requisitos establecidos para cada uno de estos casos, bajo control judicial y de acuerdo con las disposiciones del presente Código (Martínez de la Rosa et al, 2009). Esta cuestión sigue generando controversia, ya que, la disolución del contrato matrimonial por parte de la esposa hacia su marido, tiene que ser efectuado a través del esposo. No hay que olvidar que en el Islam, el matrimonio no es un sacramento como en el catolicismo, sino que es un contrato (Esposito, 2004). El esposo tiene el derecho exclusivo de finalizar el matrimonio sin causa y sin constricciones legales, con la prerrogativa de poseer tres repudios diferentes sobre una misma mujer.

Así, cuando la mujer decide poner fin al vínculo matrimonial, lo tiene que hacer a través del marido o del juez, debiendo dar una compensación económica al esposo para que éste acepte la disolución matrimonial, ya que como comentamos anteriormente, la disolución por talaq pueden ejercerla cualquiera de los dos cónyuges.

La disolución del matrimonio islámico por tatliq en la Escuela malikí se refiere a los casos en que es la esposa la que ejerce su voluntad de poner fin a su relación conyugal, por las causas enunciadas en el CF y éstas son: incumplimiento del esposo de las cláusulas estipuladas en el contrato matrimonial; por perjuicio; por falta de manutención por parte de esposo; por ausencia del esposo; por defecto o enfermedad de uno de los cónyuges y la imposibilidad para la vida íntima; y, por juramento de continencia del marido, desestimiento o abandono (Art. $98 \mathrm{CF}$ ).

Desde el punto de vista de la revocabilidad o irrevocabilidad, la disolución matrimonial por talaq, siempre según la Escuela malikí presente en el $\mathrm{CF}$, éste es revocable cuando es ejercido por el marido, permitiéndole recuperar a la mujer en el tiempo de espera (idda) que será de tres meses si en momento de la disolución por talaq pronunciada por el esposo, ésta no tiene la menstruación, mientras que, si la tiene será 
de tres períodos completos (Art. 136 CF). Por otra parte, la disolución matrimonial por talaq, es irrevocable cuando finaliza el plazo legal de espera (idda); cuando tiene lugar antes de la consumación del matrimonio; cuando se pronuncia la triple declaración de la voluntad del esposo a cancelar el vínculo matrimonial; por mutuo acuerdo; por compensación económica de la mujer al marido; por cesión del derecho del esposo a la mujer de la facultad de disolver el matrimonio (tamlik) (Art. $123 \mathrm{CF}$ ); o por divorcio declarado mediante vía judicial (Ortiz, 2014).

La disolución del vínculo conyugal proporciona una gran inestabilidad al matrimonio y hoy, las disoluciones de los matrimonios islámicos son muy numerosas, constituyéndose un gran número de familias con mujeres solas y con sus hijos.

\subsection{La poligamia}

En referencia a la poligamia, el artículo 44 del CFM, estipula: [...] el Tribunal, por decisión justificada no susceptible de recurso, podrá autorizar la poligamia si se establece que los motivos alegados revisten efectivamente un carácter objetivo y excepcional, y que se cumplen todas las condiciones legales...”. (Esteban de la Rosa, 2009). En los países musulmanes el matrimonio es una unión que tiene rasgos religiosos y al mismo tiempo, contractuales. El derecho islámico permite la unión de un hombre con varias mujeres, hasta el límite de cuatro, como es el caso de Marruecos. Sin embargo, la poligamia es una prerrogativa exclusiva del hombre y no está permitida a las mujeres. Éstas pueden ejercer su derecho a prohibirla mediante pacto o acuerdo entre las partes como condición previa al matrimonio. Asimismo, el hombre tiene la obligación de informar a la mujer de que está casado antes de celebrarse el matrimonio, pues de lo contrario, ésta podrá exigir la anulación del mismo.

La controversia reside en averiguar si la poligamia tiene una naturaleza religiosa o cultural, pues en un país islámico como Marruecos la religión rige los ámbitos de los derechos y libertades. Pues bien, en Francia esta práctica es considerada, como señalamos anteriormente, contraria al ordenamiento jurídico por constituir un factor de desorden público y por la vulneración de los derechos fundamentales, derechos que precisamente permiten la libertad religiosa. En esta línea, los migrantes marroquíes que practican la poligamia en suelo francés, se defienden de las críticas haciendo pasar esta práctica como un rasgo propio de la religión islámica. En cuanto a su reconocimiento 
jurídico por el Convenio Franco-marroquí, Francia solo reconoce la poligamia concomitante y no la simultánea, es decir, que para celebrarse un nuevo matrimonio ha de extinguirse el anterior (Labaca, 2009).

\section{El reconocimiento del CFM en la sociedad de destino y su impacto sobre las mujeres migrantes marroquíes}

Las mujeres migrantes no son un grupo homogéneo, ya que, tienen diversos estatutos jurídicos, debido a que pueden ser: nacionales o binacionales; migrantes voluntarias o involuntarias; regulares o irregulares; temporales o permanentes; menores o adultas. Sus derechos dependen de su estatus jurídico-social. La protección jurídica de las migrantes tiene límites que, a menudo, pone a las mujeres en situaciones de opresión, tanto por ser mujeres como por ser extranjeras. La migración de mujeres marroquíes solas, frecuentemente, tiene como causas la falta de trabajo, la violencia física y psíquica; y la falta de libertad, siendo la búsqueda de un trabajo en el extranjero, un medio para lograr liberarse o para adquirir derechos. Otra barrera es el desconocimiento de las leyes, tanto en Marruecos como en Francia, en este aspecto, las mujeres ignoran a dónde deben dirigirse para que les informen de sus derechos. Desde la primera década del siglo XXI, Marruecos ha efectuado una serie de reformas jurídicas que afectan al estatuto de las mujeres, tales como el CFM o el Código de la Nacionalidad, en el que éstas, pueden transmitir la nacionalidad a sus hijos salidos de matrimonios mixtos (Elmadmad, 2011).

En la UE, la estabilización de las poblaciones musulmanas ha sido unas de las cuestiones primordiales con el objetivo de asegurar la continuidad y la cohesión del conjunto social europeo. El cuestionamiento de las estructuras familiares musulmanas pone sobre el tapiz que la integración en la sociedad de destino apela precisamente, a una desintegración del sistema familiar musulmán en situación de inmigración estable, mientras que paralelamente, se produce la transmisión de la nacionalidad marroquí por parte de la esposa practicada por la vía de los matrimonios mixtos y la reagrupación familiar, garantizando la transmisión del orden familiar y la herencia cultural marroquí (Foblets, 1996). Estos dos procesos de signo contrario muestran las divergencias que se producen en ambas comunidades, en materia de integración. Así, la UE ha definido el reagrupamiento familiar (DOCE, 22 de septiembre de 2003), como uno de los aspectos fundamentales de la inmigración, en la cual, los Estados miembros no están obligados a 
conceder la carta de estancia permanente a los inmigrantes reagrupados, sino solamente, a aquéllos que la hayan tenido durante cinco años, y por lo tanto, los Estados podrán denegar el derecho a trabajar durante el primer año y prohibir la renovación de la carta en caso de separación de la pareja (Lesselier, 2004).

En Francia, los flujos de inmigración están ordenados por el Code de l'entrée et du séjour des étrangers et du droit d'asile, con entrada en vigor el 10 de febrero de 2015. El reagrupamiento familiar está regulado por los artículos 29, 30 y 31 de la Orden de 1945, que rige la inmigración en Francia, enmendada numerosas veces, y por el Decreto de julio de 1999 y la Circular del 1 de marzo de 2000 (OFII, 2015). La reagrupación familiar en Francia es el procedimiento por el cual un extranjero que resida regularmente en el territorio, durante al menos 18 meses, puede solicitar el derecho de reagrupación para su cónyuge. La reagrupación familiar adquiere su auge en 1974, con el cierre de fronteras a la inmigración laboral, reactivada en 1976. Ésta, permite a un extranjero residente en Francia de forma legal, hacer venir a un familiar que puede ser su cónyuge, un ascendiente o sus descendientes menores.

Las repercusiones de la ley respecto a las inmigrantes marroquíes en el país de destino son de diverso calado, colocando a estas mujeres en situaciones de subordinación y opresión, facilitadas por varios factores, entre los que se encuentran: los estereotipos normativos; los acuerdos bilaterales entre el país de origen y el de destino, la reagrupación familiar y la doble violencia.

Como hemos señalado, la estancia y residencia de las mujeres inmigrantes marroquíes, está casi siempre vinculada a requisitos familiares o conyugales. Los estereotipos normativos remiten a las mujeres a la asunción de los modelos sociales de madre o esposa, orientándolas a la vida en familia y en convivencia estable. Pero la desigualdad de los cónyuges se mantiene y las mujeres inmigrantes son discriminadas tanto en el interior de la pareja como por la sociedad en la que se insertan. Muchas mujeres están en situación de violencia infringida por parte de su marido extranjero en Francia o francés, siendo amenazadas por su cónyuge de la pérdida de la carta de estancia por separación. Muchas de ellas sufren chantaje y violencia física, psíquica, sexual y enclaustramiento, esclavitud doméstica o disolución unilateral del matrimonio (Lesselier, 2004). 
La legislación francesa en materia de concesión de permisos de estancia o residencia favorece las estrategias de matrimonios de conveniencia para la obtención de "papeles" en el marco del Convenio Franco-marroquí, a través del reconocimiento del matrimonio musulmán. Las mujeres que utilizan estas estrategias pueden padecer situaciones como las anteriormente descritas, ya que, la renovación de los permisos de residencia están condicionados al ejercicio de la vida en común (Artículo L313-12. Modificado por la Ley $n^{o}$ 2014-873 de 4 de agosto 2014-Art. 47). En consecuencia, deben tener un domicilio común, presentando los documentos que así lo demuestren, además del documento de identidad o de residencia del marido. El lapso de tiempo que dura esta situación de plena dependencia por parte de la esposa puede renovarse después de un año de la concesión del permiso de estancia, o puede ser retirada en caso de ruptura de la vida en común.

La regulación jurídica francesa sobre el otorgamiento de permisos de estancia por reagrupación familiar y motivos de matrimonio, sitúa a las mujeres inmigrantes en situaciones de dependencia concediendo todo el poder al esposo en el comienzo de la estancia en Francia. El inicio de las gestiones administrativas tiene un plazo máximo de solicitud de 3 meses a partir de la llegada a Francia y hasta la concesión del permiso de estancia, pueden pasar varios meses. Las mujeres que padecen violencia o repudio por parte del marido, al emerger las relaciones del patriarcado tradicional de suma autoridad del esposo se suman, además, a un aislamiento de la mujer inmigrante sobre todo si no habla la lengua francesa. Otras variables conducen a las inmigrantes a estas situaciones de dependencia y violencia: la falta de recursos; el desempleo (la ley no permite el derecho al trabajo de las reagrupadas en esta modalidad), el divorcio unilateral o repudio; y la imposibilidad de un retorno al país de origen, donde las mujeres divorciadas están estigmatizadas. En este sentido, las mujeres divorciadas o abandonadas pierden el derecho a la renovación de su permiso de estancia, sin que haya mediado una situación de violencia conyugal, pasando a una situación de "sin papeles", pudiendo, incluso, ser conducidas a la frontera (Mihalich, 2001).

Finalmente, la doble violencia padecida por algunas mujeres inmigrantes, se traduce por una parte, en el favorecimiento de la dependencia legal de las mujeres con respecto al marido, al ser obligatoria la vida en común con el cónyuge, y esta situación lleva con frecuencia a la violencia; y por otro lado, la discrecionalidad, los largos 
plazos en la concesión y las condiciones de renovación de los permisos de estancia o residencia por parte de la Administración francesa, propicia la ilegalización de estas mujeres con la pérdida de los permisos de estancia, convirtiéndose en mujeres "sin papeles" y sometidas a la violencia institucional.

\section{Conclusiones}

Los procesos migratorios internacionales ponen al descubierto todo un abanico de particularidades de las comunidades inmigrantes que las sociedades de destino deben enfrentar. Los sistemas jurídicos de la Unión Europea y de Francia asumen los estatutos jurídicos de base personal procedentes de países musulmanes, como es el caso del Código de Familia Marroquí (CFM), en virtud de los Convenios Bilaterales firmados por Francia y Marruecos. El Derecho Internacional Privado permite el reconocimiento del CFM en la sociedad de destino, mientras que, el propio sistema jurídico francés está obligado a la preservación de su base fundamental, la defensa de los valores emanados de los Derechos Humanos y de la Ilustración. Los elementos de extrañeza que suponen el reconocimiento de la disolución del matrimonio islámico y de la poligamia ponen a prueba un ordenamiento jurídico y una sociedad de destino, que tiene como consecuencia un enclaustramiento jurídico de las mujeres marroquíes inmigrantes, en la aplicación simultánea de la ley marroquí y de la ley francesa, dando lugar a situaciones de doble violencia y de dependencia, pues muchas de las mujeres marroquíes migrantes en Francia, utilizan la modalidad del reagrupamiento familiar para alcanzar la sociedad de destino, donde las mujeres representan casi más de la mitad de la comunidad inmigrada de origen marroquí. 


\section{Referencias}

Ajaaouani, N. (2012, octubre). Situación de la mujer en Marruecos tras las reformas del nuevo código de familia. Una perspectiva histórico-social y jurídica. En M. Cabrera Espinosa \& J.A. López Cordero (Eds.), IV Congreso Virtual sobre Historia de las Mujeres. Asociación de amigos del archivo histórico diocesano de Jaén, Jaén.

Benradi, M. (2005). Genre et droit de la famille. Les droits des femmes dans la Moudawana. De la révision de 1993 à la reforme de 2003. En H. Alami M’Chichi et al (Eds.). Féminin-Masculin. La marche vers l'égalité au Maroc 1993-2003 (pp. 17-90). Rabat: Friedrich Eberich Stiftung.

Bouchareb, H. (2003). Les effets du divorce en droit international dans les rapports entre les États européens francophones et les États maghrébins (Memoria de Máster). Paris: Université Paris VIII.

Carbonnier, J. (1994). Sociologie juridique. Paris: Coll. Quadrige. PUF (1 ${ }^{\mathrm{a}}$ Ed.).

Coulson, N. J. (1998). Historia del derecho islámico. Barcelona: Bellaterra.

Décret $n^{\circ}$ 83-435 DU 27. (1983). Convention entre la République française et le royaume du Maroc relative au statut des personnes et de la famille et à la coopération. Descargado de http://www.hcch.net/upload/2fr-ma.pdf.

Elmadmad, K. (2011). Femmes, migrations et droits au Maroc. CARIM. Notes d'analyse et de synthèse, No. 01. Descargado de http://cadmus.eui.eu/bitstream/handle/1814/15586/CARIM_ASN_2011_01.pdf? $\underline{\text { sequence }=1}$

Esposito, J. L. (2004). El Islam. 94 preguntas básicas. Madrid: Alianza Editorial.

Esteban de la Rosa, G. (dir.) (2009). Código Marroquí de la Familia. Jaén: Universidad de Jaén.

Esteban de la Rosa, G; Ouhida, J; Oual Ali, K.; Sahir, T. (2009): La nueva Mudawana marroquí: entre tradición y modernidad. Traducción comentada del Código de la Familia de 2004. Revisión linguiística de Vidal Castro, F. Junta de Andalucía. Colección "Materiales" 5. Consultada el 14/10/2015.

Fariñas, Mª J. (1991). La Sociología del Derecho de Max Weber. Madrid: Civitas.

(1996). Sistemas jurídicos: elementos para un análisis sociológico.

Madrid: Universidad Carlos III. 
Foblets, M.C. (1996). Familles-Islam Europe. Le droit confronté au changement. Paris: L’Harmattan.

Juynboll, Th. W. (2002). Encyclopédie de l'Islam. Leiden: Brill. Nouvelle Édition. Tome X.

Labaca Zabala, Ma L. (2009). El matrimonio polígamo y su repercusión en el derecho español. Revista Jurídica de Castilla y León, 18.

Lesselier, C. (2004). Femmes migrantes en France. Les Cahiers du CEDREF, 12,45-59.

Maíllo Salgado, F. (2005). Diccionario de derecho islámico. Gijón: Ediciones Trea.

Martínez Almira, Ma M. (2006). Derecho procesal malikí hispanoárabe. Nápoles: Edizione Scientifici Italiane.

Mihalich, L. (2001). No exit: the plight of battered Maghrebi immigrant women in France (Tesis doctoral). Nueva York: Woodrow Wilson School of Public and International affairs.

Milliot, L. y Blanc F.-P. (2001): Introduction à l'étude du droit musulman. Paris: Dalloz. $2^{\text {a }}$ Edición.

Najm, M.C. (2010). Le sort des répudiations musulmanes dans l'ordre juridique français. Droit et idéologie(s). Droit et cultures.

http://droitcultures.revues.org/2070

Office Français de 1’Immigration et de 1’Intégration (OFII) (2015). París: http://www.ofii.fr/i

Ortiz Vidal, M. D. (2014): El repudio en el Código de Famila de Marruecos y la aplicación del derecho marroquí en la UE. Cuadernos de Derecho Transnacional. 6 (2), 201-244.

Pareja, F. M. (1954): Islamología. Madrid: Editorial Razón y Fé. Tomo II.

Rahal-Sidhoum, S. (2004). L'éprouve étrangère est de facto écartée du choix du lieu de résidence de la famille en contradiction avec l'article 215 du code civil. En C. Lesselier (Ed.). Femmes migrantes en France. Paris: Université Paris 13.

Ruiz de Almodóvar, C. (2005). El derecho privado en los países árabes. Códigos de Estatuto personal. Granada: Universidad de Granada.

Soriano, R. (1997). Sociología del Derecho. Barcelona: Ariel.

Weber, M. (2005). El político y el científico. Madrid: Alianza Editorial. 
El reconocimiento del Código de la Familia Marroquí en Francia y su impacto sobre las mujeres migrantes marroquíes

[Página en blanco por razones de paginación] 